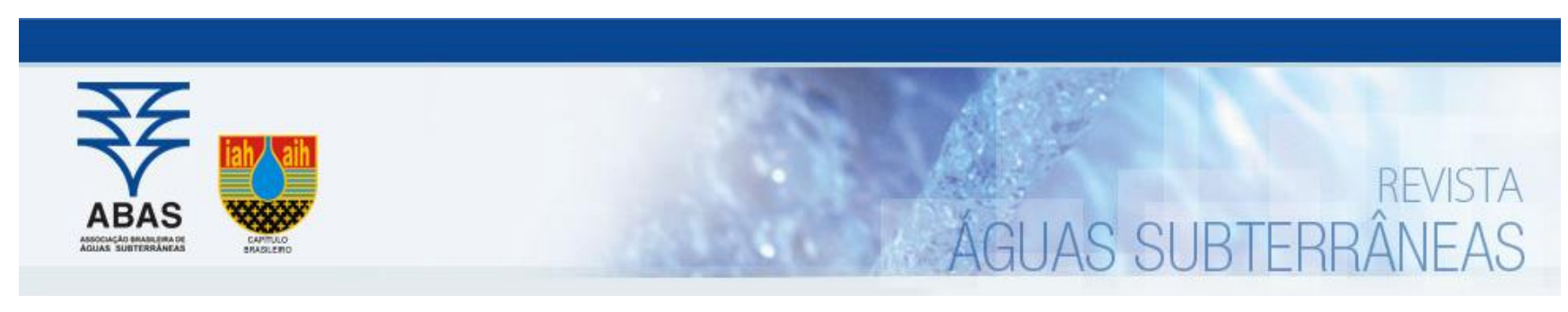

Artigos

\title{
Caracterização do comportamento da cafeína em meio não saturado a partir do emprego de ensaios de coluna
}

\section{Characterization of caffeine behavior in unsaturated soils from the use of column tests}

\author{
Antonioni Duarte Lins Guerrera1,2; Cleuda Custódio Freire2; Bruno Cavalcante Costa2; José Vitor Ribeiro Rocha2® \\ 1 Universidade de Brasília (UnB), Brasília, DF \\ 2 Universidade Federal de Alagoas (UFAL), Maceió, AL
}

$\bowtie$ tonigeologia@gmail.com, ccf@ctec.ufal.br, brunocavalcante55@gmail.com, vitor.rr@hotmail.com

\author{
Palavras-chave: \\ Aquíferos. \\ Indicadores de contaminação. \\ Percolação. \\ Contaminantes Emergentes. \\ Café. \\ Ensaios de tubulação.
}

\section{Keywords:}

Aquifers.

Contamination Indicators.

Percolation.

Emerging Contaminants.

Coffee.

Piping tests.

Revisão por pares.

Recebido em: 30/08/2020.

Aprovado em: 19/12/2020.

\begin{abstract}
Resumo
Uma forma de verificar a origem de um contaminante às águas subterrâneas é através da presença da cafeína no meio, uma vez que a mesma é um indicador direto de contaminação por efluentes domésticos. Neste contexto, este trabalho tem como objetivo analisar a influência do meio não saturado na percolação deste composto e relacionar sua presença em poços de captação de água subterrânea. Para tal, foi utilizado sedimentos das unidades geológicas aflorantes da Formação Barreiras e dos Depósitos Litorâneos e realizados ensaios de coluna em três diferentes tamanhos (0,5 / 1,0 e 2 metros), onde foi lançada solução de cafeína pré-definida em cada uma delas (para cada tipo de sedimento específico) e coletado em seu final. Os resultados mostram que para a formação Barreiras (caracterizada por possuir intercalações de argila e silte), a cafeína foi retida apenas no primeiro metro de sedimentos, onde percebeu-se que a presença ou ausência de elementos no meio, são fundamentais para influenciar na capacidade de retenção do composto neste tipo de sedimento. Já os Depósitos Litorâneos (sedimentos não consolidados) removeram a cafeína de maneira progressiva, permitindo inferir que para este tipo de formação, a profundidade dos sedimentos é fator predominante na remoção de tal composto. Quando analisado tais resultados com a quantidade de cafeína presente nos poços de águas subterrâneas, constatou-se que, quando não associado a outros tipos de processos, a quantidade de cafeína lançada tanto nos Depósitos litorâneos quanto na Formação Barreiras foi inferior a $350 \mathrm{mg} / \mathrm{L}$ e $100 \mathrm{mg} / \mathrm{L}$, respectivamente.
\end{abstract}

\begin{abstract}
One way of verifying the origin of a potential contaminant in the groundwater is the presence of caffeine, since it is a direct indicator of contamination by domestic effluents. In this context, this work aims to analyze the influence of the unsaturated soils in the percolation of this compound and to relate its presence in underground water wells. To this end, were used sediments from outcropping geological units of the Barreiras formation and Depositos Litorâneos, where were subjected to column tests in three different sizes (0.5/ 1.0 and 2 meters) and the pre-defined coffee solution was launched in each of them (for each type of specific sediment) and collected at its end. The results show that for the Barreiras formation (characterized by having intercalations of clay and silt), caffeine was retained only in the first meter of sediments, where it was noticed that the presence or absence of elements in the soil, are fundamental to influence the capacity compound retention in this type of sediments. The Depósitos Litorâneos (unconsolidated sediments) removed caffeine in a progressive manner, allowing to infer that for this type of formation, the depth of sediments is a predominant factor in the removal of such compound. When analyzing these results with the amount of caffeine present in groundwater wells, it was found that when not associated with other types of processes, the amount of caffeine released both in the Depósitos Litorâneos and in the Barreiras Formation was less than 350 $\mathrm{mg} / \mathrm{L}$ and $100 \mathrm{mg} / \mathrm{L}$, respectively.
\end{abstract}

DOI:http:/dx.doi.org/10.14295/ras.v35i1.29949

\section{INTRODUÇÃO}

As águas subterrâneas são hoje uma das principais fontes de abastecimento das cidades. A sobreexplotação associada à urbanização impacta não só aspectos quantitativos de tais recursos, como ocasiona também uma piora na qualidade dos aquíferos (LE VO, 2007). Diversas fontes de contaminação como resíduos industriais, fossas sépticas, aterros sanitários e poços de captação poluídos (XUAN, 2001) podem estar associados ao processo de piora da qualidade deste tipo de manancial, porém definir a causa principal de contaminação é de extrema importância para criar medidas mitigadoras para a gestão das águas subterrâneas.

Neste sentido, compostos denominados de PPCPs (Pharmaceuticals and Personal Care Products), que incluem, dentre 
outros, a cafeína, bifenóis, codeína, coprostanol, colesterol, antioxidantes, detergentes não biodegradáveis, fragrâncias e desinfetantes, estão sendo amplamente utilizados para associar a presença dos mesmos com o esgoto doméstico (WILKISON et al., 2002).

A presença da cafeína nas águas subterrâneas é um dos compostos que representa um indicador em potencial de contaminação de águas domésticas neste tipo de recurso (SEILER et al.,1999; TUBBS et al., 2004). O motivo se dá pelo fato de que tal composto possui características que a distingue de outros possiveis indicadores de origem diversas, no caso, a de estar associada unicamente com a interação entre água e esgotos. A utilização deste parâmetro como indicador de contaminação por efluente doméstico é relativamente recente e vem cada vez mais sendo utilizado. Tanto em pesquisas que levaram em consideração análises de águas superficiais (IDE, 2013; WILKISON et al., 2002; QUEIRÓZ, 2016; PAPADOPOULOU-MOURKIDOU et al., 2001) como em águas subterrâneas (SEILER et al.,1999; TUBBS et al., 2004; PAPADOPOULOU-MOURKIDOU, et al, 2001), pôde-se associar a cafeína como um indicador de contaminação da água por efluente doméstico, seja como complemento para as análises físico-químicas tradicionais ou como ferramenta única para o monitoramento da qualidade d'água (QUEIROZ, 2016).

De tal forma, o meio em que o fluido tende a percolar tem papel fundamental na concentração final do soluto, onde, para o caso da cafeína, reações como sorção e biodegradação, principalmente esta última, agem como principal causa de mudança de concentração do composto (FANG et al., 2012; RAMIL et al., 2010; XU et al., 2009; LIN et al., 2010; ZEARLEY e SUMMERS, 2012). Parâmetros como profundidade de percolação do fluido, granulometria, massa específica, permeabilidade e porosidade, tendem a influenciar sobremaneira tais reações, alterando por fim, a concentração final do soluto.
Visando determinar as possíveis relações da cafeína com o meio, é preciso entender os principais agentes que influenciam nas interações físico-químicas e biológicas que interferem na concentração final da mesma. Dessa forma foi feito um ensaio de colunas para os dois tipos de sedimentos que representam os principais aquíferos da cidade de Maceió, aquífero Barreiras (associado a sedimentos terciários da Formação Barreiras - Enb) e aquífero de sedimentos de Praia e Aluvião (associado a sedimentos quaternários dos Depósitos Litorâneos - QI), onde foram experimentadas três alturas distintas de colunas para cada um dos sedimentos, visando compreender a influência da altura (ou profundidade de percolação) na concentração final. Parâmetros físico-químicos do solo como granulometria, massa específica, umidade, Ferro (Fe), Cobre (Cu), Manganês ( $\mathrm{Mn})$, Sódio (Na), quantidade de matéria orgânica, entre outros, também foram analisados a fim de determinar qual sua influência na capacidade de reter a cafeína. Ao fim, uma análise da presença da cafeína nas águas subterrâneas de Maceió, através de poços de captação foi realizada, visando compreender a relação entre a concentração observada nos poços em questão e aquelas obtidas como resultado do experimento de colunas

\section{METODOLOGIA}

\section{1. Área de Estudo}

Os sedimentos considerados na pesquisa referem-se à Formação Barreiras e aos depósitos litorâneos presentes cidade de Maceió, a primeira recobre grande parte do município, estando a segunda associada aos vales de rios, planícies flúviolagunar e à planície litorânea (Figura 1). Tais sedimentos são responsáveis pela recarga dos principais aquíferos da região. As mesmas afloram em grande parte da costa brasileira alagoana e, consequentemente, do município de Maceió (aflorando em mais de $90 \%$ de todo seu território).

Figura 1 - Área de estudo associada as formações geológicas
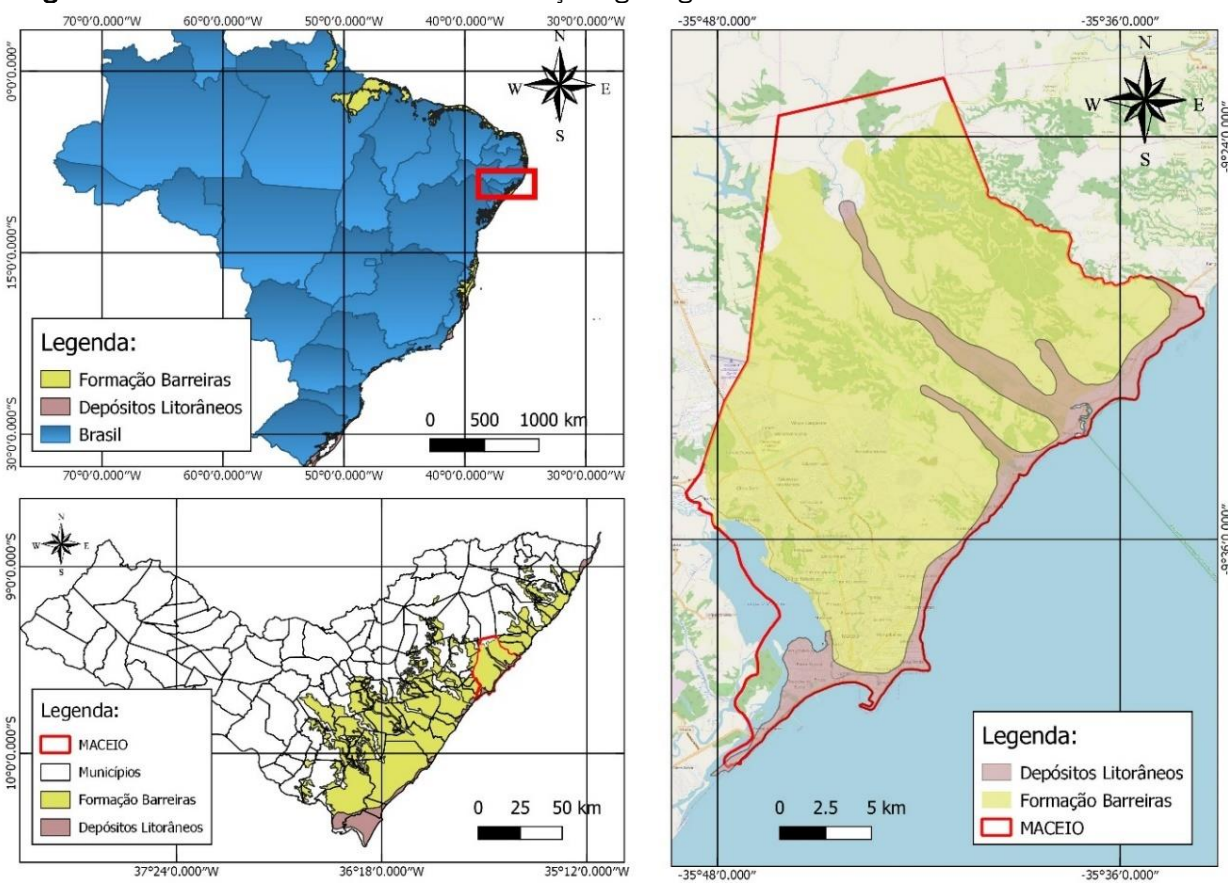


\subsection{Escolha dos sedimentos e seleção dos poços de capta- ção para análise da cafeína}

A escolha dos sedimentos a serem utilizados no ensaio de coluna baseou-se na importância que os mesmos têm em servir como meio de percolação não saturado para a recarga dos principais aquíferos do município. Para isso foi feita uma análise quantitativa de poços de captação de água subterrânea dentro do município de Maceió. Além disso, foi levada em consideração a constatação da presença da cafeína na área de estudo (LOPES, 2018; COSTA, 2019). Tais estudos objetivaram identificar a relação e evolução da cafeína associada à contaminação doméstica, utilizando poços de captação de água subterrânea localizados sob as formações geológicas aflorantes citadas.

A Figura 2 evidencia os poços que captam água dos principais aquíferos da região associados às principais formações geológicas aflorantes e os poços utilizados em estudos anteriores. Destaca-se também a quantidade muito superior de poços na Formação Barreiras quando comparado aos Depósitos Litorâneos.

Desta forma, para a análise da relação entre a litologia da região com a concentração de cafeína, será feita a coleta de água em três dos nove poços estudados por Lopes (2018). Com isto, pretende-se estimar uma relação da quantidade de cafeína que foi lançada nos ensaios de coluna com as obtidas nas análises dos poços. Vale ressaltar que os mesmos poços também foram analisados por Costa (2019).

Considerando-se a possibilidade de comparação entre o resultado dos ensaios de coluna com aqueles obtidos nos poços, optou-se por aplicar o perfil litológico dos mesmos (Figura 3).

Figura 2 - Poços existentes nas formações geológicas e coleta dos sedimentos

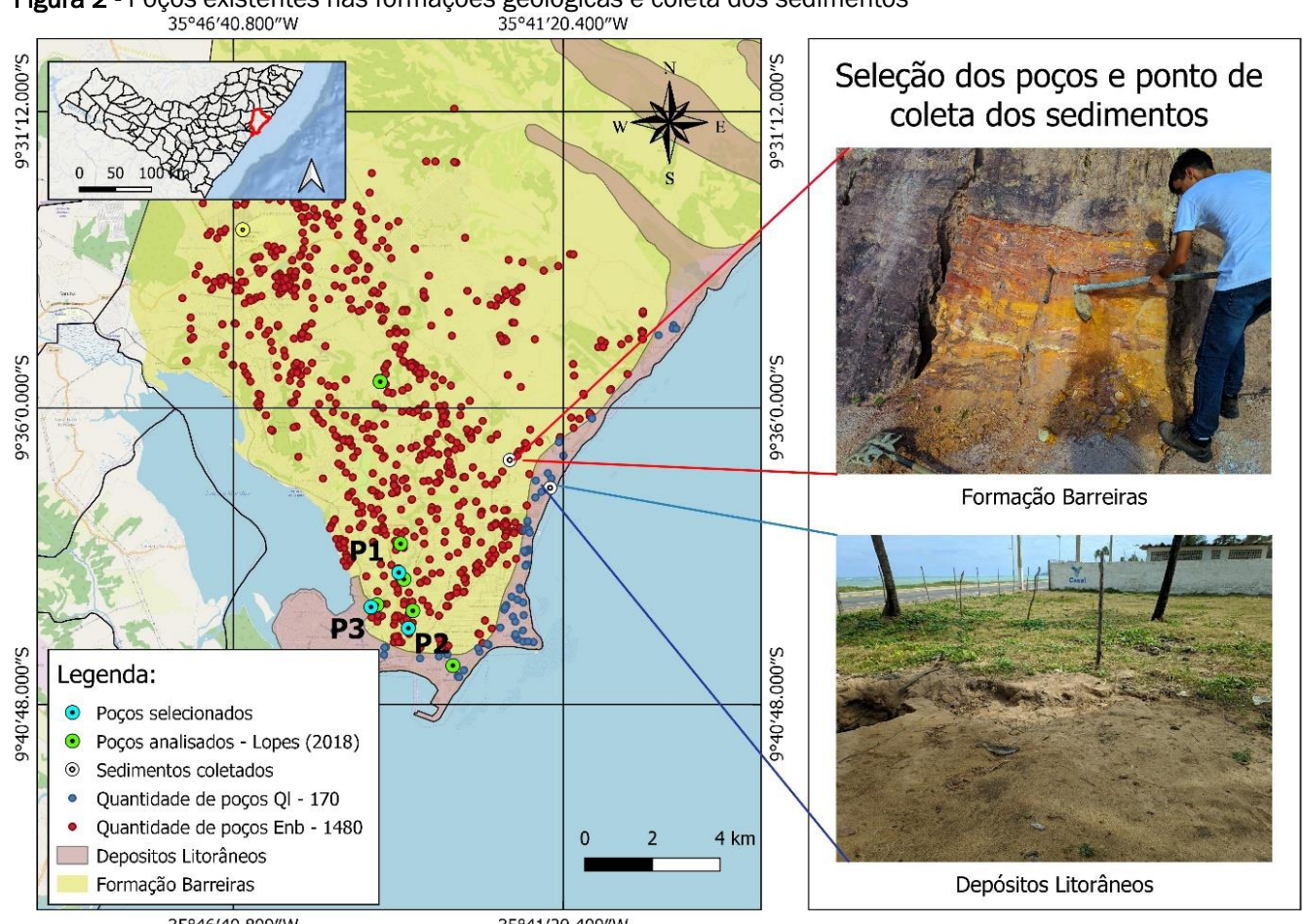

$35^{\circ} 46^{\prime} 40.800^{\prime \prime} \mathrm{W}$ 
Figura 3 - Poços selecionados para análise de cafeína. Fonte: Secretaria de Estado do Meio Ambiente e dos Recursos Hídricos de Alagoas (modificado)

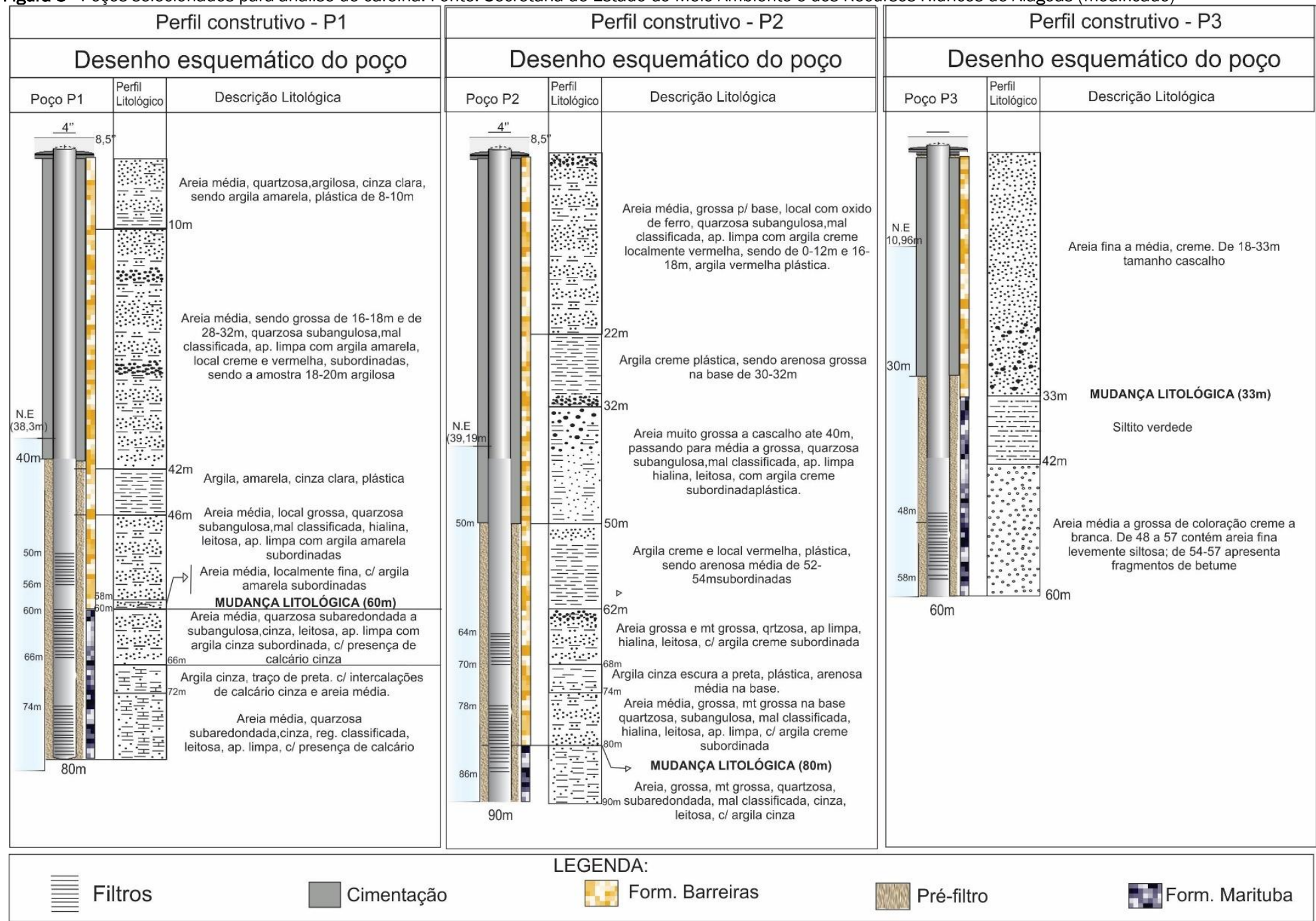




\subsection{Determinação dos parâmetros físico-químico dos sedi- mentos selecionados}

A análise do solo em laboratório para a determinação das principais propriedades texturais e físico-químicas do meio foi realizada, com o propósito de avaliar possíveis influências na concentração da cafeína. Nas análises foram determinadas características como: granulometria, umidade, massa específica (Tabela 1), Matéria Orgânica Total e concentrações de algumas propriedades químicas como potássio, sódio, fósforo, entre outros (Tabela 2).

Tabela 1 - Parâmetros físicos dos sedimentos

\begin{tabular}{ccccccccc}
\hline Sedimentos & $\begin{array}{c}\text { Argila } \\
(\%)\end{array}$ & $\begin{array}{c}\text { Silte } \\
(\%)\end{array}$ & $\begin{array}{c}\text { Areia } \\
\text { fina (\%) }\end{array}$ & $\begin{array}{c}\text { Areia } \\
\text { média (\%) }\end{array}$ & $\begin{array}{c}\text { Areia grossa } \\
(\%)\end{array}$ & $\begin{array}{c}\text { Pedregulho } \\
(\%)\end{array}$ & $\begin{array}{c}\text { Massa } \\
\text { específica }\end{array}$ & $\begin{array}{c}\text { Umidade } \\
(\%)\end{array}$ \\
\hline Barreiras & 33,55 & 16,05 & 34,89 & 13,50 & 2,90 & 0,26 & 2,657 & 4,172 \\
$\begin{array}{c}\text { Depósitos } \\
\text { Litorâneos }\end{array}$ & - & 0,99 & 9,93 & 85,17 & 3,78 & 0,13 & 2,653 & 0,092 \\
\hline
\end{tabular}

Tabela 2 - Parâmetros químicos e biológicos analisados nos sedimentos

\begin{tabular}{|c|c|c|c|c|c|c|c|c|c|c|c|c|c|c|c|c|}
\hline $\begin{array}{l}\text { Sedimen- } \\
\text { tos }\end{array}$ & $\begin{array}{l}\text { M.O } \\
\text { Total } \\
(\%)\end{array}$ & $\begin{array}{c}\mathrm{K} \\
(\mathrm{ppm})\end{array}$ & $\begin{array}{c}\mathrm{Na} \\
(\mathrm{ppm})\end{array}$ & $\begin{array}{c}\mathrm{P} \\
(\mathrm{ppm})\end{array}$ & $\begin{array}{c}\mathrm{PH} \\
\text { (em } \\
\text { água) }\end{array}$ & $\begin{array}{c}\mathrm{Ca}+ \\
\mathrm{Mg} \\
(\mathrm{meq} / 1 \\
\text { 00mL) }\end{array}$ & $\begin{array}{c}\mathrm{Ca} \\
(\mathrm{meq} / 1 \\
00 \mathrm{~mL})\end{array}$ & $\begin{array}{c}\mathrm{Mg} \\
(\mathrm{meq} / 1 \\
00 \mathrm{~mL})\end{array}$ & $\begin{array}{c}\mathrm{Al} \\
\text { (meq/1 } \\
00 \mathrm{~mL})\end{array}$ & $\begin{array}{c}\mathrm{H}+\mathrm{Al} \\
(\mathrm{meq} / 1 \\
00 \mathrm{~mL})\end{array}$ & $\begin{array}{c}\mathrm{Fe} \\
(\mathrm{ppm})\end{array}$ & $\begin{array}{c}\mathrm{Cu} \\
(\mathrm{ppm})\end{array}$ & $\begin{array}{c}\mathrm{Zn} \\
(\mathrm{ppm})\end{array}$ & $\begin{array}{c}\mathrm{Mn} \\
(\mathrm{ppm})\end{array}$ & $\begin{array}{l}\text { C.T.C } \\
* \\
\text { efe- } \\
\text { tiva }\end{array}$ & $\begin{array}{l}\text { C.T.C } \\
\text { em } \\
\text { pH } 7\end{array}$ \\
\hline Barreiras & 0,38 & 13 & 13 & 2 & 5,5 & 1,5 & 0,5 & 1 & 0,08 & 0,2 & 8,29 & 0,66 & 0,29 & 0,23 & 1,67 & 1,79 \\
\hline $\begin{array}{l}\text { Depósi- } \\
\text { tos Lito- } \\
\text { râneos }\end{array}$ & 0,27 & 8 & 71 & 72 & 8,4 & 4,6 & 2,1 & 2,5 & 0,0 & 0,0 & 0,46 & 5,7 & 1,37 & 4,56 & 4,93 & 4,93 \\
\hline
\end{tabular}

\subsection{Ensaios de coluna em meio não saturado}

Para determinar o quanto os sedimentos em questão agem na sua capacidade de reter a concentração da cafeína, uma simulação da percolação da cafeína foi realizada em laboratório, através de tubos PVC de $200 \mathrm{~mm}$ de diâmetro.

As amostras são representações deformadas do meio, de forma que não representam o arranjo e distribuição inicial de quando estavam in situ. A simulação ocorreu em duas etapas distintas, na primeira as tubulações foram preenchidas com sedimentos típicos dos Depósitos Litorâneos e na segunda com os sedimentos referentes à formação Barreiras.

0 experimento foi realizado em três alturas distintas, sendo de 0,5m; 1,0m e 2,0 m (Figura 4). A simulação para as três distintas alturas foi feita para ambos os sedimentos.

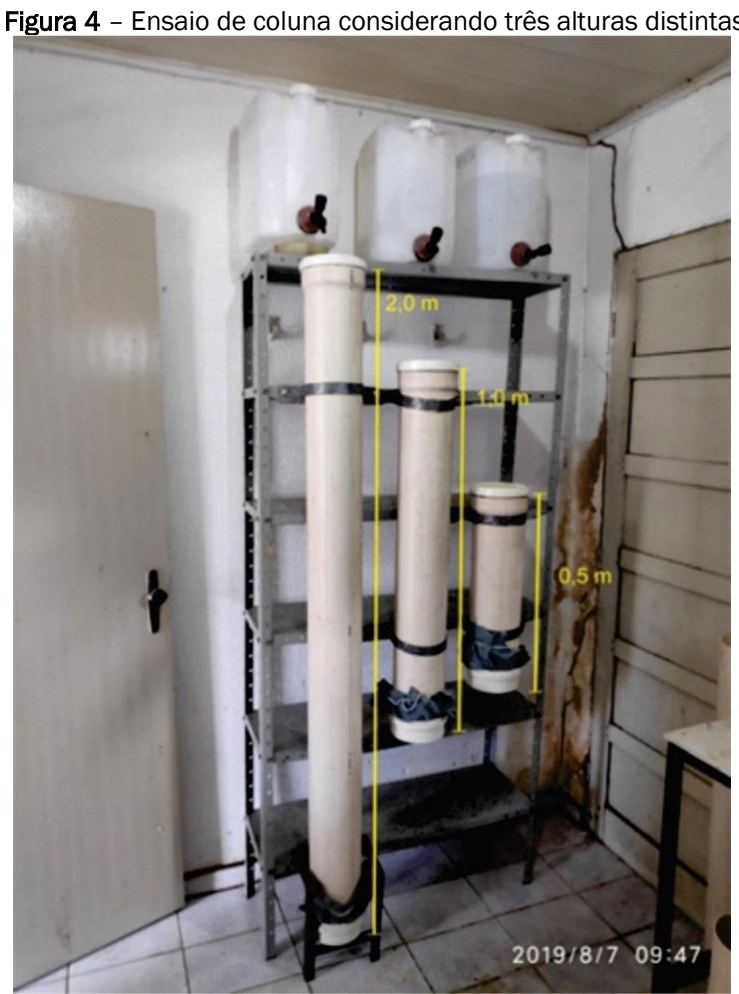


Em ambos os sedimentos foram realizadas análises de amostras em branco para averiguar concentrações iniciais da cafeína seja no solo, na água ou em ambos. A quantidade de análises realizadas para cada tubulação em ambos os sedimentos foi apenas uma, fator esse que limitou a análise estatística dos experimentos.

Na realização do experimento, a concentração inicial da cafeína foi pré-estabelecida, onde o contaminante foi diluído em água corrente e adicionado na parte superior da tubulação e coletado em seu final. Como não houve um controle da vazão lançada, a solução em questão foi adicionada de maneira gradual através de um recipiente de 2 litros, despejando a solução à medida que a lâmina d'água na parte superior iria sendo rebaixada.

A quantidade de água utilizada em cada tubulação foi de 2 litros para 0,5m; 4 litros para de $1 \mathrm{~m}$ e 8 litros para tubulação de $2 \mathrm{~m}$, para ambos os tipos de sedimentos e para os experimentos em branco e com concentração pré-estabelecida. Para as tubulações em que foram lançados mais de dois litros, o procedimento foi repetido, de forma que não houve intervalo de tempo entre as repetições.

O critério para definir a concentração inicial da cafeína foi tomada com base na metodologia de análise da mesma, onde se procurou lançar a cafeína de forma que a concentração final fosse superior ao limite mínimo de quantificação (LQ) préestabelecido. Em caso de ser superior ao limite máximo, utilizou-se o fator de diluição para determinar a concentração da mesma. Como as concentrações iniciais variaram de acordo com o tipo de análise ou de sedimento estudado, as concentrações utilizadas nesta pesquisa foram sempre de acordo com o tamanho da tubulação.

Para evitar o fluxo turbulento e prover a percolação da solução nas tubulações, foram colocados tampões na parte superior com furos de 1 a 2 milímetros de diâmetro. Na parte inferior, também foram colocados tampões de PVC com furos de 1 a 2 milímetros de diâmetro para permitir a saída da água. Para evitar a passagem de sedimentos de granulometria média a grossa na coleta, foram colocadas mantas geotêxtis no final de cada uma das tubulações. Foi utilizado funil na parte inferior para facilitar a coleta da solução.

\subsection{Coleta e análise da cafeína}

Uma vez realizados os ensaios de coluna, as amostras foram coletadas em recipientes com capacidade para $500 \mathrm{~mL}$, identificadas e mantidas devidamente refrigeradas até a análise laboratorial, conforme o que consta no Guia Nacional de Coleta e Preservação de Amostras (ANA, 2011).

Para a análise da cafeína, a metodologia utilizada foi a disposta em "Official methods of analysis of the Association of Official Analytical Chemists" (AOAC, 2005), baseando-se na extração com clorofórmio em meio alcalino e determinação por espectrofotometria na região do ultravioleta.

O limite de quantificação (LQ) (Figura 5) determinado no método em questão foi obtido através da curva padrão da cafeína, este último associado aos valores de absorbância da metodologia. O LQ determinado foi de $2 \mathrm{mg} / \mathrm{L}$ de cafeína, correspondente a um valor de absorbância de $0,029 \mathrm{~nm}$, onde valores abaixo disso não tiveram valor de concentração correspondente. 0 valor máximo da curva foi equivalente à $6 \mathrm{mg} / \mathrm{L}$, correspondente a um valor de $0,098 \mathrm{~nm}$, onde para valores acima deste último, foi necessário a diluição da amostra para adequação à metodologia de detecção utilizada.

As análises das amostras coletadas foram feitas no Laboratório de Saneamento Ambiental (LSA/CTEC) da Universidade Federal de Alagoas (UFAL), segundo os critérios adotados por APHA (2005).

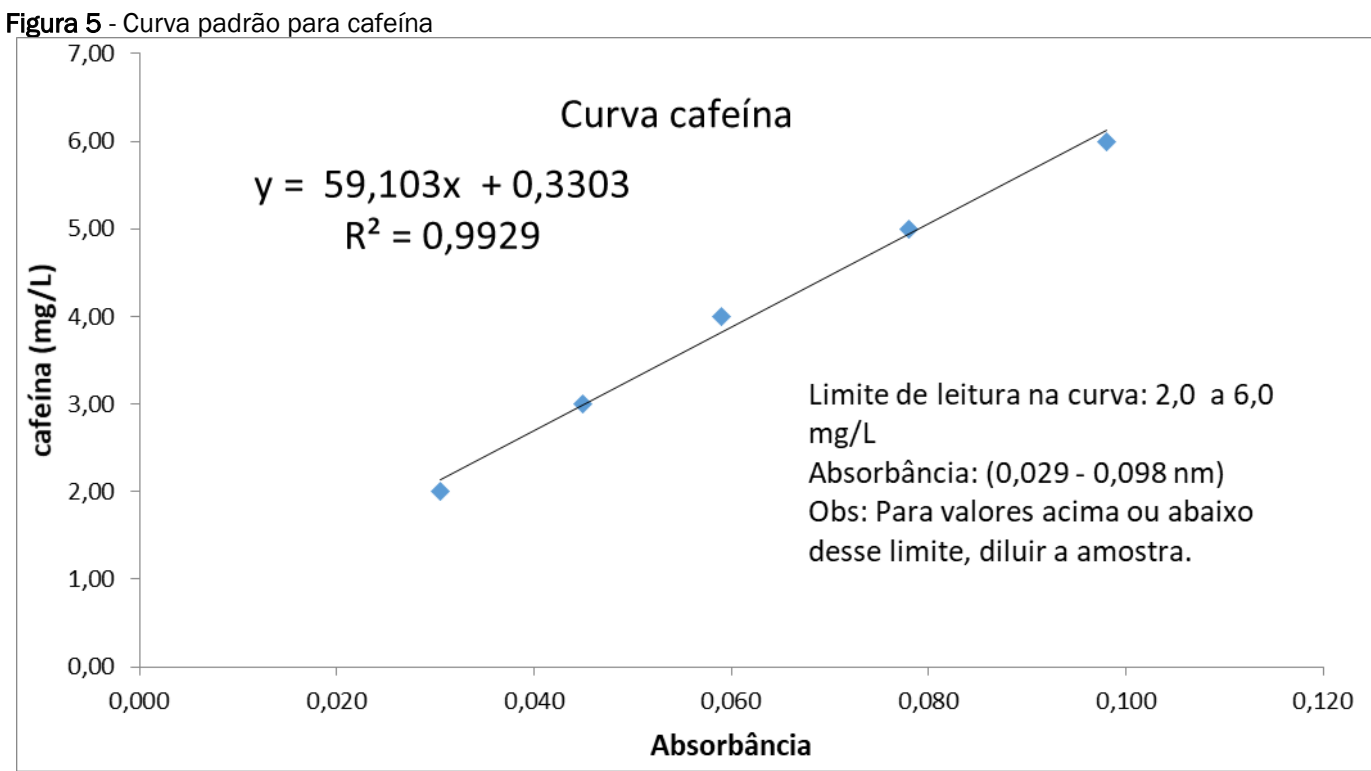




\section{RESULTADOS E DISCUSSÃO}

\subsection{Ensaios de colunas}

Para os sedimentos não consolidados dos Depósitos litorâneos $(\mathrm{Q})$, o resultado das análises das amostras em branco (sem concentração) foram todas abaixo do limite de quantificação, já para as amostras com concentrações iniciais préestabelecidas, considerando as três alturas distintas das tu- bulações, os resultados das análises estão dispostos na Tabela 3 .

Considerando a quantidade (em $\mathrm{mg} / \mathrm{L}$ ) do contaminante que ficou retido na tubulação e subtraindo a quantidade final da solução coletada com a inicial lançada, obteve-se a seguinte relação (Figura 6):

Tabela 3 - Resultado dos ensaios para Depósitos Litorâneos (QI)

\begin{tabular}{cccccccc}
\hline & $\begin{array}{c}\text { Amostras em } \\
\text { branco }\end{array}$ & $\begin{array}{c}\text { Depósitos Litorâneos } \\
\text { Amostras concentradas }\end{array}$ \\
$\begin{array}{c}\text { Tubulação } \\
(\mathrm{m})\end{array}$ & $\begin{array}{c}\text { Concentração } \\
\text { final }(\mathrm{mg} / \mathrm{L})\end{array}$ & $\begin{array}{c}\text { Absorbância } \\
(\mathrm{nm})\end{array}$ & $\begin{array}{c}\text { Concentração } \\
\text { Inicial } \\
(\mathrm{mg} / \mathrm{L})\end{array}$ & $\begin{array}{c}\text { Concentração } \\
\text { Final }(\mathrm{mg} / \mathrm{L})\end{array}$ & $\begin{array}{c}\text { Concentração } \\
\text { retida }(\mathrm{mg} / \mathrm{L})\end{array}$ & $\begin{array}{c}\text { Capacidade } \\
\text { de retenção } \\
(\%)\end{array}$ & $\begin{array}{c}\text { Concentração inicial } \\
\text { por volume de } \\
\text { tubulação }\left(\mathrm{mg} / \mathrm{L} / \mathrm{m}^{3}\right)\end{array}$ \\
\hline 0,5 & $<\mathrm{LQ}$ & 0,029 & 9,6 & 2,04 & 7,56 & 78,75 & 611,46 \\
1,0 & $<\mathrm{LQ}$ & 0,050 & 40 & 3,28 & 36,72 & 91,8 & 1273 \\
2,0 & $<\mathrm{LQ}$ & 0,030 & 78,5 & 2,1 & 76,4 & 97,32 & 1250 \\
\hline
\end{tabular}

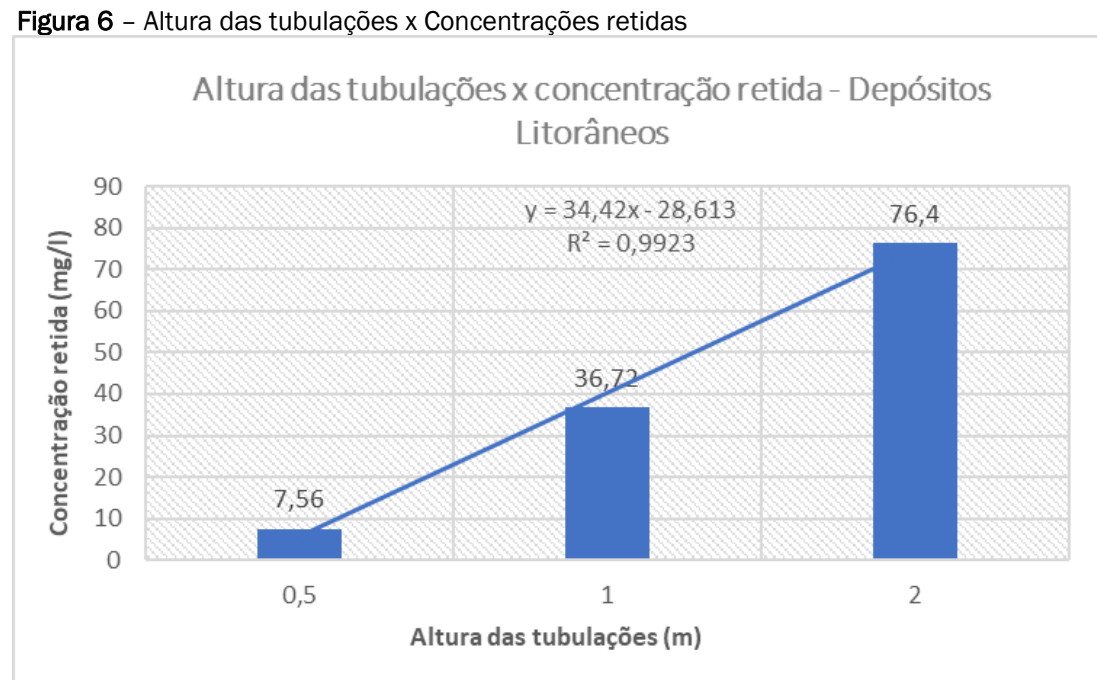

Nota-se que para os sedimentos de depósitos litorâneos se manteve uma relação direta entre o tamanho da tubulação e a concentração final, mostrando uma diferença considerável de retenção entre os 0,5 e 1 metro, ocasionando uma retenção de 29,16 mg, 21,6 mg a mais quando comparado com o primeiro $0,5 \mathrm{~m}$. Quando comparado a quantidade retida no segundo metro de coluna (ou seja, do intervalo que vai do primeiro ao segundo metro) tem-se uma retenção de 39,68 mg, valor este muito próximo ao que ficou retido no primeiro metro de tubulação $(36,73 \mathrm{mg})$.

Dessa forma, para os sedimentos analisados, o primeiro 0,5 metro não teve papel fundamental na retenção da cafeína, onde considerando 1 metro de tubulação a retenção maior esteve entre os 0,5 e 1 metro de altura. Um outro ponto a se considerar é que a relação de concentração por volume foi o dobro para as tubulações de 1 e 2 metros quando comparado com a de 0,5, o que permite manter a análise comparativa para estas duas tubulações, porém, limita quando se compara a relação de concentração e volume com a tubulação de meio metro.

Para os sedimentos da Formação Barreiras (Enb), o resultado das análises das amostras em branco (sem cafeína) também foram todas abaixo do limite de quantificação. Já para as amostras com concentrações pré-estabelecidas o resultado encontra-se na Tabela 4.

Da mesma forma que foi analisada para os depósitos litorâneos, a figura 7 apresenta a relação da quantidade $(\mathrm{mg} / \mathrm{l})$ que ficou retida na tubulação em relação à quantidade inicial lançada. 
Tabela 4 - Resultados dos ensaios para Formação Barreiras

\begin{tabular}{|c|c|c|c|c|c|c|c|}
\hline \multirow[b]{3}{*}{$\begin{array}{l}\text { Tubulação } \\
(\mathrm{m})\end{array}$} & \multicolumn{6}{|c|}{ Formação Barreiras } & \multirow[b]{3}{*}{$\begin{array}{l}\text { Concentração inicial } \\
\text { por volume de } \\
\text { tubulação }\left(\mathrm{mg} / \mathrm{L} / \mathrm{m}^{3}\right)\end{array}$} \\
\hline & \multirow{2}{*}{$\begin{array}{c}\text { Amostras em } \\
\text { branco } \\
\text { Concentração } \\
\text { final (mg/L) }\end{array}$} & \multicolumn{5}{|c|}{ Amostras concentradas } & \\
\hline & & $\begin{array}{l}\text { Absorbância } \\
\text { (nm) }\end{array}$ & $\begin{array}{l}\text { Concentração } \\
\text { Inicial (mg/L) }\end{array}$ & $\begin{array}{l}\text { Concentração Final } \\
(\mathrm{mg} / \mathrm{L})\end{array}$ & $\begin{array}{l}\text { Capacidade de } \\
\text { retenção (\%) }\end{array}$ & $\begin{array}{l}\text { Concentração } \\
\text { retida }(\mathrm{mg})\end{array}$ & \\
\hline 0,5 & $<\mathrm{LQ}$ & 0,005 & 20 & $<\mathrm{LQ}$ & $\sim 100$ & 20 & $1273 \mathrm{mg} / \mathrm{L} / \mathrm{m}^{3}$ \\
\hline 1,0 & $<\mathrm{LQ}$ & 0,073 & 200 & 4,64 ×20 = 92,89* & 53,55 & 107,11 & $6369 \mathrm{mg} / \mathrm{L} / \mathrm{m}^{3}$ \\
\hline 2,0 & $<\mathrm{LQ}$ & 0,097 & 400 & $6,0 \times 50=300 * *$ & 25 & 100 & $6369 \mathrm{mg} / \mathrm{L} / \mathrm{m}^{3}$ \\
\hline
\end{tabular}

*A concentração resultante da absorbância foi de $4,64 \mathrm{mg} / \mathrm{l}$, porém foi utilizado um fator de diluição de 20x.

**A concentração resultante da absorbância foi de $6,0 \mathrm{mg} / \mathrm{l}$, porém foi utilizado um fator de diluição de $50 x$.

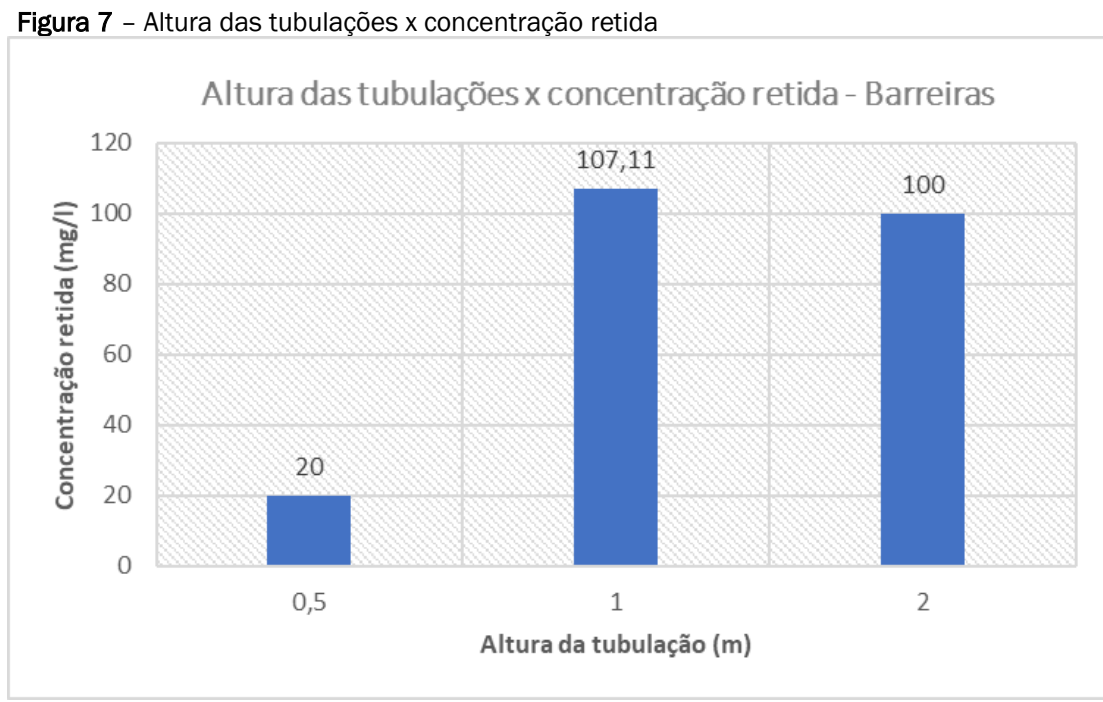

Para a análise em questão, vale ressaltar que as $20 \mathrm{mg} / \mathrm{L}$ lançadas na tubulação no primeiro 0,5 metro foram totalmente retidas, o que dificulta a análise uma vez que não se sabe a quantidade real de concentração possível de ser retida no primeiro 0,5 metro, a única conclusão possível é que para concentrações de até $20 \mathrm{mg} / \mathrm{L}$ os primeiros 50 centímetros de sedimentos serão suficientes para reter $100 \%$ do contaminante.

Já para o primeiro metro de tubulação a concentração retida foi de $107,11 \mathrm{mg} / \mathrm{L}$ dos $200 \mathrm{mg} / \mathrm{L}$ lançados. Se for levado em consideração que o primeiro 0,5 metro foi suficiente para reter $20 \mathrm{mg} / \mathrm{I}$ de cafeína (podendo possuir uma capacidade de retenção maior), pode-se dizer que entre 0,5 e 1 metro de tubulação teve uma capacidade máxima de retenção de 87,11 $\mathrm{mg} / \mathrm{L}$, podendo ser menor uma vez que para o experimento de 0,5 sabe-se que foi retido todo o contaminante lançado.

Observa-se que para a tubulação de 2 metros a quantidade de contaminante retida foi similar à tubulação de 1 metro ( $100 \mathrm{mg} / \mathrm{L})$, o que se admitiu que entre o primeiro e segundo metro de tubulação os sedimentos da formação Barreiras não apresentaram eficiência em sua capacidade de reter a cafeína.

Visando entender o motivo da baixa capacidade de reter a cafeína na tubulação de dois metros da formação Barreiras, e sabendo que a presença de Ferro é capaz de diminuir a capacidade de biodegrabilidade (HEBIG et al., 2017) foi realizado uma análise deste elemento nos sedimentos utilizados em cada uma das tubulações, o resultado encontra-se na Tabela
5:

Tabela 5 - Concentração de ferro nas tubulações da Formação Barreiras

\begin{tabular}{cccc}
\hline Tubulação & $0,5 \mathrm{~m}$ & $1 \mathrm{~m}$ & $2 \mathrm{~m}$ \\
Ferro $(\mathrm{mg} / \mathrm{kg})$ & 1,22 & 1,32 & 1,79
\end{tabular}

Nota-se que a concentração de ferro na tubulação de dois metros foi $46,7 \%$ a mais que a tubulação de 0,5 metros e de $35,6 \%$ a mais que a tubulação de um metro, o que permite inferir que a baixa capacidade de retenção para a tubulação de dois metros possa estar associada a uma maior concentração de ferro.

Em termos de concentração por volume de tubulação, os resultados foram iguais para as colunas de 1 e 2 metros e diferente para de 0,5 metro, permitindo análises comparativas para as duas primeiras.

\subsection{Relação da cafeína com as propriedades físico-químicas dos sedimentos}

Como visto na Tabela 1, a formação Barreiras é a que possui maior quantidade de fração argila e silte, representando em torno de $49,60 \%$ de sua composição total, contra aproximadamente $1 \%$ dos sedimentos litorâneos. Isso reflete a baixa permeabilidade do meio para o primeiro tipo de sedimento e a alta para o segundo. Essa característica possibilita um tempo de retenção (tempo em que a solução é despejada no topo da 
tubulação até ser coleta em sua base) do composto com o solo maior, consequentemente aumentando as possíveis quantidades de reações, seja através da sorção ou biodegradação. Esse aspecto possivelmente refletiu na alta capacidade de retenção da cafeína para os sedimentos da formação Barreiras nos experimentos realizados e a relativa baixa capacidade de reter a cafeína para os Depósitos Litorâneos. 0 tempo de retenção medido para cada uma das colunas e seus respectivos sedimentos estão apresentados na Tabela 6:

Tabela 6 - Tempo de retenção do contaminante

\begin{tabular}{ccc}
\hline $\begin{array}{c}\text { Tubulação } \\
(\mathrm{m})\end{array}$ & $\begin{array}{c}\text { Tempo de retenção } \\
(\mathrm{Ql})\end{array}$ & $\begin{array}{c}\text { Tempo de retenção } \\
(\text { Enb) }\end{array}$ \\
\hline 0,5 & $5 \mathrm{~min}$ & $1 \mathrm{~h} \mathrm{15min}$ \\
1,0 & $9 \mathrm{~min} \mathrm{30s}$ & $1 \mathrm{~h}$ \\
2,0 & $21 \mathrm{~min}$ & $2 \mathrm{~h} \mathrm{05min}$ \\
\hline
\end{tabular}

Uma observação importante a ser feita é que o tempo de retenção para a tubulação de 0,5 metro para os sedimentos da Formação Barreiras foi superior à tubulação de 1,0 metro. Isso pode ser justificado pelo fato de se tratar de amostras deformadas, onde é possível que para a tubulação de menor tamanho, a fração argila nela tenha sido proporcionalmente superior às outras granulometrias, retendo assim, por mais tempo, a solução.

Uma outra característica comparativa considerando as propriedades dos sedimentos é a umidade. Sedimentos da Formação Barreiras apresentaram-se mais úmidos que dos litorâneos, com 4,172\% de umidade contra 0,092\% deste último. Como a umidade está associada à capacidade de proliferação de fungos e bactérias, aumentando assim a capacidade de biodegradação, é possível que a umidade da formação Barreiras tenha contribuído para uma maior eficiência na retenção da cafeína.

Algumas outras relações entre a cafeína e os sedimentos po- dem ser feitas com base na Tabela 2 . Nota-se que a quantidade de matéria orgânica total (\%) foi superior nos sedimentos da formação Barreiras o que pode ter contribuído para sua maior eficiência na remoção da cafeína por processo de biodegradação.

Já para a concentração de Ferro, Hebig et al (2017) mostrou que quando analisado em meio saturado, para sedimentos contendo areia revestida de ferro, a cafeína não sofreu nenhum processo de remoção. No caso em questão, a maior concentração de ferro foi encontrada na Formação Barreiras. Se for considerado que a quantidade de ferro é superior na tubulação de dois metros em relação a de 0,5 e 1,0 metro, nota-se uma retenção menor por parte da maior coluna, permitindo inferir que a presença de ferro em meio não saturado foi responsável em inibir a remoção da cafeína para o caso em questão, resultando em valores de cafeína similar ao de um metro de tubulação.

Alguns outros elementos foram analisados e estão dispostos na Tabela 2, porém não foi encontrado em literatura alguma relação deles com a cafeína. Ainda assim, vale ressaltar que a diferença entre as concentrações destes parâmetros é mínima e que estudos mais aprofundados para cada um desses componentes são fundamentais para avaliação da influência que cada um pode causar na remoção da cafeína para os sedimentos aqui estudados.

\subsection{Análise dos poços de captação e possíveis implicações na área de estudo}

As análises das amostras dos 3 poços também levaram em consideração análises anteriores de cafeína para os mesmos poços, no caso, realizada por Lopes (2018). Os resultados estão dispostos na Tabela 7.

Tabela 7 - Resultado das análises dos poços de captação

\begin{tabular}{ccccc}
\hline Poço & Formação Geológica & $\begin{array}{c}\text { Cafeína (mg/L) } \\
\text { (AUTORES, 07/2019) }\end{array}$ & $\begin{array}{c}\text { Cafeína (mg/L) } \\
\text { (LOPES, set/2018) }\end{array}$ & $\begin{array}{c}\text { Nível } \\
\text { Estático } \\
\text { (NE) }\end{array}$ \\
\hline P1 & Barreiras & $<$ LQ* & 3,88 & $38,3 \mathrm{~m}$ \\
P2 & Barreiras & $<\mathrm{LQ}$ & 2,09 & $39,19 \mathrm{~m}$ \\
P3 & Depósitos Litorâneos & $<\mathrm{LQ}$ & 2,19 & $10,96 \mathrm{~m}$ \\
\hline * Limite de quantificação & & &
\end{tabular}

Quando analisado o perfil do poço (P3) (figura 3) que está localizado nos sedimentos de Depósitos Litorâneos, percebeuse que a posição do filtro encontra-se entre 48 e 58 metros de profundidade. Ainda assim, os primeiros 10,96 metros de profundidade (distância da superfície até o lençol freático associado ao meio não saturado, considerando que o efluente foi lançado em superfície) correspondem aos sedimentos aqui analisados, onde todo o possível contaminante teve que percolar até atingir o lençol.

Analisando a equação da reta gerada na regressão linear (Gráfico 2), observa-se que para uma profundidade de 10,96 metros (meio não saturado), pressupõe-se que tais sedimentos seriam responsáveis em reter aproximadamente $350 \mathrm{mg}$. Desta forma, conforme resultado explicito na Tabela 7, para análise do referido poço, o valor da cafeína foi inferior ao LQ (2,0 mg/L), ou seja, possivelmente a quantidade de cafeína lançada na superfície foi igual ou inferior àquela quantidade. Vale ressaltar que esse valor corresponde apenas ao meio não saturado e que o contaminante ainda teve que percolar 22 metros em meio saturado através dos depósitos litorâneos e mais 15 metros de meio saturado para os sedimentos da formação Marituba.

Se for considerada a análise que Lopes (2018) fez em setembro do mesmo ano (10 meses antes da análise aqui abordada), em que resultou em um valor de $2,19 \mathrm{mg} / \mathrm{L}$ de cafeína, pode-se inferir que a quantidade da mesma (consequentemente de efluente doméstico) lançado em superfície foi muito superior aos $350 \mathrm{mg} / \mathrm{L}$ (equivalente à capacidade de retenção). 
Uma característica marcante do aquífero dos Sedimentos de Praia e aluvião (associado aos Depósitos Litorâneos) é que são considerados rasos (lençol freático próximo à superfície, média de 4,7 metros - poços perfurados entre 2011 e 2016) e facilmente vulnerável à contaminação. Logo, a capacidade de remover a cafeína ao longo da profundidade não é tão influenciável nesse tipo de sedimentos, tendo em vista a baixa profundidade do lençol, onde a vulnerabilidade do mesmo a contaminantes (principalmente de origem doméstica) pode ser fator crucial na presença de cafeína nesses aquíferos.

Já para os poços que se encontram localizados em sedimentos da formação Barreiras (P1 e P2 - Figura 3), tem-se que para o primeiro a profundidade do filtro encontra-se a partir dos 50 metros iniciais, estando os sedimentos da formação Barreiras até os 60 metros de profundidade. Como o nível do lençol freático encontra-se a 38 metros (Tabela 7), há uma zona não saturada de 38 metros e uma zona saturada de 22 metros para este tipo de sedimento.

Já para o poço 2, existe 39 metros de zona não saturada (distância da superfície até o nível do lençol) e 25 metros de zona saturada distância do NE até o primeiro filtro).

Levando-se em consideração o resultado da análise da cafeína de ambos os poços (P1 e P2), observa-se que este esteve abaixo do limite de quantificação. Porém, constatou-se, através dos ensaios de coluna, que os sedimentos da formação Barreiras se mostraram muito eficientes para o primeiro metro de sedimento (retendo em torno de $100 \mathrm{mg} / \mathrm{L}$ ). Logo, caso a quantidade de cafeína lançada em superfície tenha sido inferior a $100 \mathrm{mg} / \mathrm{L}$, a zona não saturada foi a responsável por reter tal composto em ambos os poços.

Quando analisado o resultado de Lopes (2018) para estes mesmos poços, o resultado para a cafeína foi de $3,88 \mathrm{mg} / \mathrm{L}$ para o poço P1 e 2,09 mg/L para o P2, o que se admite que a quantidade de cafeína lançada em superfície foi superior a $100 \mathrm{mg} / \mathrm{L}$ e suficiente para percolar tanto o meio não saturado quanto o meio saturado.

Uma característica do aquífero Barreiras é que possui uma considerável profundidade até encontrar o lençol freático, apresentando uma média de 43,4 metros - dados de poços perfurados entre 2011 e 2016). Logo, infere-se que mesmo com uma profundidade considerada grande até o lençol (considerando que os efluentes estão sendo lançados em superfície), a capacidade maior encontra-se no primeiro metro, e que a presença de ferro em sua composição pode facilitar a chegada da cafeína ao aquífero em questão.

Ainda comparando os resultados obtidos nos experimentos com as análises dos poços de captação subterrânea algumas considerações podem ser feitas a respeito da análise. Como dito anteriormente, a profundidade das fossas e sumidouros tendem a diminuir a espessura que os efluentes tenderiam a percolar, logo, não necessariamente a cafeína teve que percolar os metros explicitados anteriormente para cada um dos poços, podendo a mesma ter atingido o lençol de uma maneira mais rápida, dependendo da profundidade de lançamento dos efluentes domésticos.

Outro fator importante em relação às concentrações de cafeína nos poços de captação subterrânea, não está simplesmente associado ao meio em que percola e que a presença de alguns outros componentes presentes no próprio efluente tem a capacidade de atenuar ou de acelerar o processo de biodegrabilidade. Bertelkamp (2014), por exemplo, conclui que a presença de enxofre na solução consegue diminuir a biodegrabilidade da cafeína, uma vez que a mesma tem origem doméstica, onde o enxofre (presente nos detergentes) possa ter tido um papel importante no aumento das concentrações encontradas nos poços. Por outro lado, a presença de matéria orgânica acelera o processo de biodegradação (HEBIG et al., 2017), logo, por se tratar de efluentes domésticos, a presença da mesma pode ter sido capaz de acelerar esse processo, do qual resultou na diminuição das concentrações. De certa forma, dentro do próprio efluente, existem variáveis que podem influenciar na concentração da cafeína, seja em seu aumento ou na diminuição.

\section{CONCLUSÕES E RECOMENDAÇÕES}

O intuito do estudo foi analisar o comportamento da cafeína nas principais formações geológicas da área na área que envolve a região metropolitana de Maceió e comparar com resultados de análise de poços de água subterrânea. Os experimentos realizados demonstraram que a cafeína se comporta de maneira distinta de acordo com o tipo de sedimento que está sendo analisado.

Para a formação Barreiras, tipicamente mais argilosa e com presença de ferro, a cafeína foi retida apenas no primeiro metro de sedimentos, com uma taxa relaticamente alta de retenção, próxima dos $100 \mathrm{mg} / \mathrm{L}$.

Já os Depósitos Litorâneos apresentaram uma baixa taxa de remoção, porém, apresentou uma tendência linear de remoção, onde foi capaz de remover a cafeína de maneira progressiva, permitindo inferir que, para este tipo de sedimento, quanto maior for a profundidade dos sedimentos, maior será sua capacidade de reter, de forma que nenhum outro parâmetro analisado no experimento serviu como justificativa para as retenções resultantes.

Quando relacionado com as análises dos poços, percebeu-se que os valores foram abaixo do LQ, permitindo deduzir que, quando não associado a outros tipos de processos, a quantidade de cafeína lançada tanto nos Depósitos litorâneos quanto na Formação Barreiras foi inferior a 350 mg/L e 100 $\mathrm{mg} / \mathrm{L}$, respectivamente.

Foi visto que a cafeína possui a característica de ser facilmente biodegradada ou sofrer processo de sorção, o que permite deduzir que sua presença nas águas subterrâneas não deveria ser comum. Porém, mesmo possuindo tais características, observou-se que a formação Barreiras, que possui o nível do lençol freático profundo, só foi capaz de reter a cafeína 
no primeiro metro, e que a presença de ferro pode ter tido influência direta em não permitir a biodegrabilidade da mesma. Já para os Depósitos Litorâneos, observou-se que quanto maior a profundidade de sedimentos, maior será sua capacidade de retenção. Em contra partida, por possuir o nível do lençol relativamente raso, torna-se muito vulnerável à contaminação, permitindo assim encontrar a presença desse tipo de composto.

Para estudos posteriores é sugerido a utilização de amostras não deformadas, de forma que possam refletir ao máximo o comportamento da cafeína. Também se sugere uma maior quantidade de análises para cada uma das tubulações, assim como diferentes pontos de coleta dos sedimentos, de forma a estabelecer resultados estatísticos mais determinantes.

Uma outra forma de melhor correlacionar o resultado para as tubulações é considerar uma relação de "concentração e volume das tubulações" igual para todas elas, assim como analisar o comportamento da cafeína em meio saturado.

Por fim, devido sua importância como indicador de contaminação doméstica, o entendimento do comportamento da cafeína no meio não saturado pode servir de subsídio para tomada de decisão por parte dos órgãos responsáveis.

\section{REFERÊNCIAS}

ANA. Agência Nacional de Águas. Estudos Hidrogeológicos para Subsidiar a Gestão Sustentável dos Recursos Hídricos Subterrâneos na Região Metropolitana de Maceió. Relatório Final. Volume 1-4. Brasília, 2011

AOAC. Association of Official Analytical Chemists. Official methods of analysis of the Association of Official Analytical Chemists. v. 2, p. 751-757. Arlington, USA. 1995

APHA. Standard Methods for the Examination of Water and Wastewater. American Public Health Association, American Water Works Association, Water Environmental Federation, 20. ed. Washington, 2005.

BERTELKAMP, Cheryl et al. Sorption and biodegradation of organic micropollutants during river bank filtration: a laboratory column study. Water Research, v. 52, p. 231-241, 2014 https://doi.org/10.1016/i.watres.2013.10.068

COSTA, C. B. Avaliação da concentração de cafeína como indicador de contaminação ao longo do perfil de um solo. Trabalho de Conclusão de Curso (Graduação) - Centro de Tecnologia. Universidade Federal de Alagoas. Maceió, 2019.

FANG, Yu et al. Occurrence, fate, and persistence of gemfibrozil in water and soil. Environmental toxicology and chemistry, v. 31, n. 3, p. 550-555, 2012.

https://doi.org/10.1002/etc.1725

HEBIG, Klaus H. et al. Transport behavior of the pharmaceuti cal compounds carbamazepine, sulfamethoxazole, gemfibro- zil, ibuprofen, and naproxen, and the lifestyle drug caffeine, in saturated laboratory columns. Science of The Total Environment, v. 590, p. 708-719, 2017.

https://doi.org/10.1016/j.scitotenv.2017.03.031

IDE, Alessandra Honjo et al. Utilização da cafeína como indicador de contaminação por esgotos domésticos na Bacia do Alto Iguaçu. Revista Brasileira de Recursos Hídricos, v. 18, n. 2, p. 201-211, 2013.https://doi.org/10.21168/rbrh.v18n2.p201$\underline{211}$

LE VO, Phu. Urbanization and water management in Ho Chi Minh City, Vietnam-issues, challenges and perspectives. GeoJournal, v. 70, n. 1, p. 75-89, 2007. https://doi.org/10.1007/s10708-008-9115-2

LIN, Angela Yu-Chen et al. Potential for biodegradation and sorption of acetaminophen, caffeine, propranolol and acebutolol in lab-scale aqueous environments. Journal of Hazardous Materials, v. 183, n. 1-3, p. 242-250, 2010. https://doi.org/10.1016/j.jhazmat.2010.07.017

LOPES, L. L. F. Utilização da cafeína como indicador de contaminação das águas subterrâneas. Trabalho de Conclusão de Curso (Graduação) - Centro de Tecnologia. Universidade Federal de Alagoas. Maceió, 2018.

PAPADOPOULOU-MOURKIDOU, E. et al. Use of an automated on-line SPE-HPLC method to monitor caffeine and selected aniline and phenol compounds in aquatic systems of Macedonia-Thrace, Greece. Fresenius' journal of analytical chemistry, v. 371, n. 4, p. 491-496, 2001. https://doi.org/10.1007/s002160100934

QUEIRÓZ, Alvânia Barros de. Utilização da cafeína como indicador de contaminação por esgotos domésticos no Açude Bodocongó em Campina Grande. Trabalho de conclusão de curso (Graduação) - Universidade Estadual da Paraíba. Campina Grande, 2016.

RAMIL, Maria et al. Fate of beta blockers in aquatic-sediment systems: sorption and biotransformation. Environmental science \& technology, v. 44, n. 3, p. 962-970, 2010.

https://doi.org/10.1021/es9027452

SEILER, Ralph L. et al. Caffeine and pharmaceuticals as indicators of waste water contamination in wells. Groundwater, v. 37, n. 3, p. 405-410, 1999. https://doi.org/10.1111/i.17456584.1999.tb01118.x

SUMMERS, Ryan M. et al. Novel, highly specific N-demethylases enable bacteria to live on caffeine and related purine alkaloids. Journal of bacteriology, v. 194, n. 8, p. 2041-2049, 2012. https://doi.org/10.1128/JB.06637-11

TUBBS, Décio; Freire, Ronald Bastos; Yoshinaga, Sueli. Utilização da Cafeína como Indicador de Contaminação Das Águas Subterrâneas Por Esgotos Domésticos No Bairro De Piranema- 
Municipios De Seropédica E Itaguaí/RJ. Águas Subterrâneas, n. 1, 2004.

WILKISON, D.H.; ARMSTRONG, D.J.; ZAUGG, S.D.; BLEVINS D.W. Use of Wastewater Indicators to Assess the Impacts of Combinated Sewer Overflows on Two Urban Streams, 2002.

$\mathrm{XU}$, Jian et al. Adsorption and degradation of ketoprofen in soils. Journal of environmental quality, v. 38, n. 3, p. 1177 1182, 2009. https://doi.org/10.2134/jeq2008.0347
XUAN, T. V. (2001). Groundwater pollution in Ho Chi Minh City and its prevention-case study. In: VIETNAM-JAPAN WORKSHOP ON GROUNDWATER CONTAMINATION 2001, 5th June 2001. Proceedings [...]. Ho Chi Minh City, Vietnam, 2001.

ZEARLEY, Thomas L.; SUMMERS, R. Scott. Removal of trace organic micropollutants by drinking water biological filters. Environmental science \& technology, v. 46, n. 17, p. 9412-9419, 2012. https://doi.org/10.1021/es301428e 